\title{
Lessons For Industry
}

Because of their diversity and richness, these stories provide practical tips for practitioners engaged in staging conferences.

Academics and practitioners are aware that no one person has sufficient knowledge to create the innovations that are required to compete globally. Conferences facilitate conversations across individuals and groups who may not normally come together. They provide a temporal and spatial mechanism that reduces physical distance, a barrier to collaboration, enables value co-creation that drives innovation and business transformation, increases sales and networks, and provides local communities with practitioners who have enhanced knowledge and technology for use in their practices.

The suggestions to be found in these stories can assist conference organisers to provide 'out of the ordinary' social experiences and ensure they continue into the future. Ideas include:

- Know who your audience is; delegates are often highly self-directed and problem-focused.

- Consider the conference outcomes that the hosting organisation would like to achieve. This may involve setting short-term objectives and long-term legacy goals, as well as being alert to the need to adapt and be flexible.

- Welcome diverse disciplines.

- Provide engaging speakers who can deliver cutting-edge research.

- Have well thought out programs that cater to a range of needs.

- Facilitate plenty of interaction by considering how to create environments where attendees can casually speak to each other, in addition to conference dinners and informal events.

- Consider accessibility in terms of cost for early career academics and practitioners as they can gain the exposure, education and opportunities that will help them be the next generation of high achievers. 
- Create opportunities for the conference to be connected with and communicated to the wider public sphere: involve the use of media personalities; generate interest so that people ask questions; welcome the general public; capture public sentiment before and after the conference; connect delegates with government and industry.

These insights and tips can inform a conference business model that seeks to value conferences and assists in realising their full potential, at the same time acknowledging their power as transformative social network spaces.

\section{Conceptualising An Expanded Business Model For Conferences}

Business models are useful for capturing, mapping and understanding the full value of entities (Osterwalder, Pigneur \& Tucci 2005). Conferences are entities that are not always fully appreciated or understood by their many stakeholders. Therefore, we believe that conceptualising a business model of conferences is a useful exercise to take into account the complexity shown in Table 1. Boons and Lüdeke-Freund (2013) argue that business models support the strategic marketing of innovative processes, products and services, and can be adapted to provide competitive advantage. Through an extensive literature review they identified three broad streams of business models: organisational business models used as a strategic management tool to improve a company's value chain; technological business models that focus on the consequences of particular technologies in terms of how firms organise to earn profits; and strategy-oriented business models that create and deliver customer value (Boons \& LüdekeFreund 2013, p. 10). From this review they argue that a generic business model incorporates four elements:

- Value offering: the value offered to customers by means of goods and services

- Supply chain: the business infrastructure, and the structure and management of supplier relationships 
- Consumer interface: the structure and management of customer relationships

- Financial model: the costs and benefits from the above three elements and their distribution to stakeholders in the firm.

The stories in this book and our previous research suggest that the application of a business model to conferences may look something like Figure 2. We have drawn on the findings of Boons and Lüdeke-Freund (2013) to develop this conference business model. The four elements are elaborated below.

DIAGRAM 2 CONFERENCE BUSINESS MODEL (CBM)

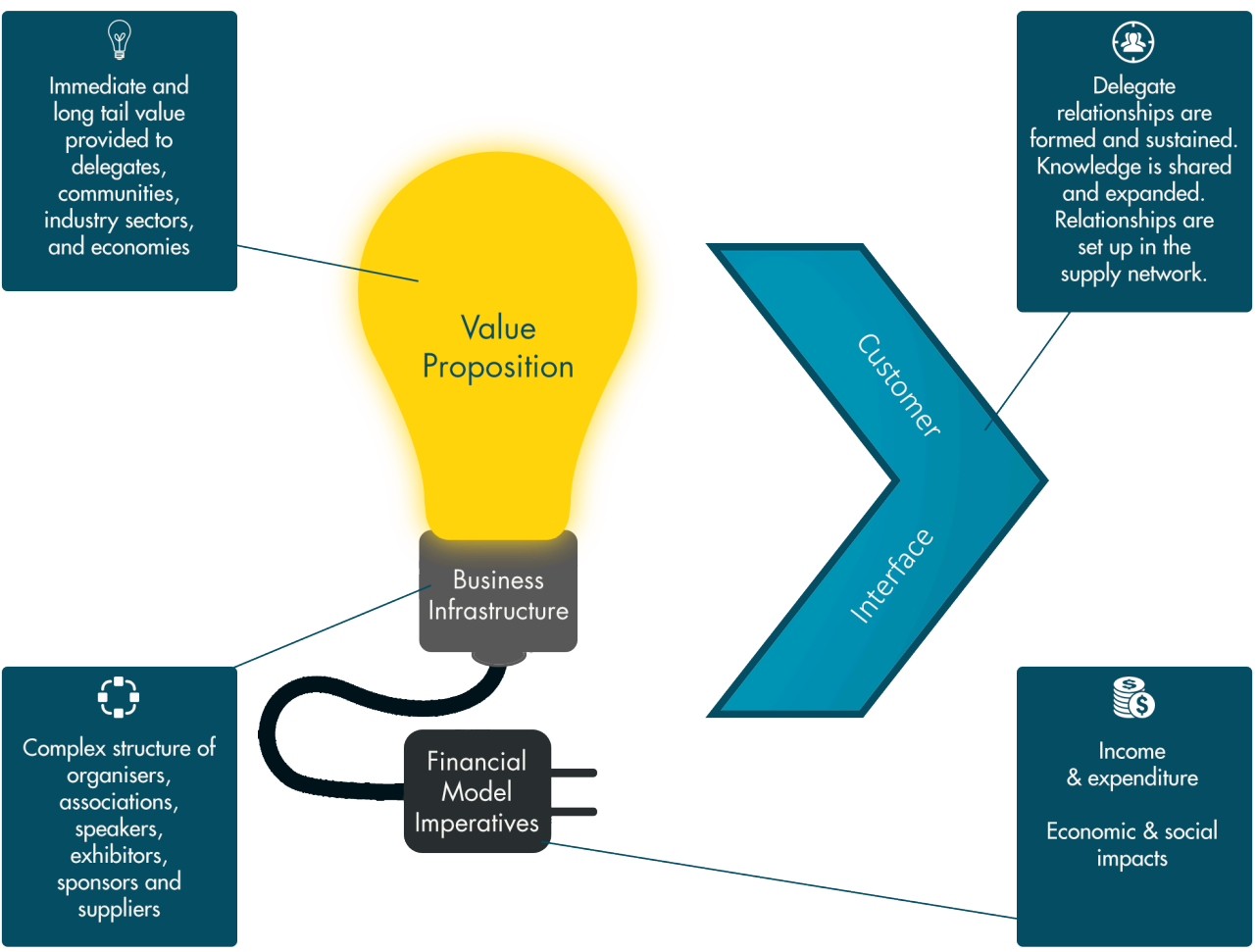


The value proposition gives an overall view of a company's bundle of products and services that provide measurable social value in concert with economic value (Osterwalder et al. 2005). In the context of conferences, the traditional value measure of tourism contribution is the tip of the value proposition iceberg. The bulk of the value is offered by means of knowledge and networking opportunities via sessions, plenaries, workshops, trade exhibitions, various intellectual activities and a social program which leads to immediate and long tail outcomes of wider societal and economic benefit. The value proposition is facilitated through dialogue that occurs temporally and spatially throughout the course of the event. During and after the conference the production and consumption of value continues among participants and an associated network of actors.

Business infrastructure dictates how the activities and resources of the conference are structured and managed. It represents a complex network of suppliers, service providers and other supporting units that perform the functions vital for producing the tangible and intangible services that support the core activities required by conference attendees (Baltacioglu et al. 2007). 'Business infrastructure portrays the network of cooperative agreements with other companies necessary to efficiently offer value' (Osterwalder et al. 2005, p. 18). These may include IT support, food and beverage suppliers, venue operator, exhibitors and sponsors.

The customer interface is twofold: (1) It reflects the attendee's ability to take responsibility for their consumption and distribution of knowledge and practices pre-, during and post-conference; (2) It describes the various means of the conference to connect with attendees and explains how a conference establishes links between itself and its different attendee segments - academics, practitioners, organisers, associations, exhibitors, sponsors.

The financial model reflects an appropriate distribution of economic costs and benefits among actors involved in the business model and also accounts for the conference's economic and social impacts (Maas \& Boons 2010). The financial model describes the revenue flows for venues, suppliers, sponsors, exhibitors and attendees. 
Given the many different types of conferences staged globally, the CBM has been presented somewhat generically to allow for empirical refinement. Theoretically, the CBM provides a basic set of principles which need to be fulfilled in order to facilitate a successful conference that generates both short-term and long-term societal and economic benefits. At the heart of the CBM is knowing that physical co-presence is important for having powerful and complex forms of interaction in which both language and nonverbal communication is involved. This enables the unique establishment of common reference frames and moments of serendipity that drive innovation and social change.

The CBM's practical contribution lies in the creation of concepts and tools that can help managers to capture value, communicate objectives to stakeholders, design for legacy, and react to competitors to improve existing conference outcomes. We encourage others to build on this work to advance the development of the CBM. 